\title{
Knowledge Gaps as regards Hepatitis C Virus: A Health Awareness Campaign among Cairo University Students
}

\author{
Mona El Lawindi, Eman El Far, Suzan Hagag
}

Department of Public Health and Community Medicine, Faculty of Medicine, Cairo University, Egypt

\begin{abstract}
Background: Public awareness campaigns (PACs) are considered useful tools in raising awareness of youth towards hepatitis viruses; and plays an important role in its elimination.

Objectives: to assess the knowledge and raise the awareness of freshmen students attending Cairo University for the academic year 201612017 towards HCV. Method: Cross sectional study was conducted among 1649 students; a self-administered questionnaire was used to identify youth's knowledge regarding HCV. This was followed by a PAC entitled "Cairo University free from Hepatitis C" using variety of health education materials in the form of brochures, video films and short seminars. Results: Mean total knowledge percent score was $51 \pm 17.6$ percent. The main source of HCV literacy was the internet (36\%), followed by health care workers (23.8\%). Conclusion: moderate level of knowledge regarding HCV was observed among studied Cairo University students. It is recommended to empower health care workers with appropriate communication and health education skills to improve public awareness regarding $\mathrm{HCV}$.
\end{abstract}

Key words: Health literacy, Health awareness campaign, hepatitis $C$, Youth health

Corresponding author: Suzan HagagEmai Email : suzan.hagag@gmail.com

\section{Introduction}

Health literacy (HL) is considered to be the ability of people to access and use information to make proper health decisions. ${ }^{1}$ It was found that a large proportion of the public have low health literacy with increasing frequency of hospital admission and increasing morbidity and mortality. So, they need to be empowered by information to take better health decisions. ${ }^{2}$ Communication skills by both recipient and sender of health care information are considered to be a major factor in the exchange of health care information. ${ }^{3}$

European Center for Prevention and Control has demonstrated that Health literacy has an important role in the field of infectious diseases. ${ }^{4}$ Low health literacy leads to decrease interest in the use of preventive services such as screening tests, increase risk of chronic diseases, increase in the use of emergency services, poor compliance to treatment, and all affect health outcomes. US Department of Health and Human Services highlighted the need for community health education with expansion in access for HCV testing and treatment. $^{5}$

Public awareness campaigns (PACs) may be helpful in raising awareness of the public towards hepatitis viruses and is considered to have an important role in elimination of hepatitis. ${ }^{6}$

Intersectoral collaborations are needed through information exchange, policy development, and implementation of preventive programs. $^{7}$

New WHO data has demonstrated that 325 million people worldwide are living with chronic hepatitis B virus (HBV) or hepatitis $\mathrm{C}$ virus $(\mathrm{HCV})$ infection. In 
2015, 1.75 million people were newly infected with HCV so the global number of $\mathrm{HCV}$ infected people has been increased to 71 million. ${ }^{8}$ Over 200.000 are living with chronic HCV in New York, $50 \%$ of them haven't knowledge regards their health condition. ${ }^{9}$ The highest prevalence of hepatitis $\mathrm{C}$ virus (HCV) infection in world was found in Egypt. ${ }^{10}$ It has been happened through infection of Egyptians with $\mathrm{HCV}$ through mass campaign by parenteral antischistosomal therapy via incomplete sterilized needles in the 1960s through the early 1980s. The DHS of 2015 demonstrated that the seroprevalence of $\mathrm{HCV}$ in the age groups $15-59$ years was $10 .{ }^{11}$

Globally, Prevention of blood-borne infections is an important public health issue. ${ }^{12}$ Youth all over the world are particularly vulnerable to blood borne diseases facing risk of $\mathrm{HIV} / \mathrm{HCV}$ infections due to social stigma, barriers to access services, limited availability of youth-friendly information and services regards safer sexual intercourse and safe injection. Preventing blood-borne infections among youth is a complex issue. So it is recommended by many international health organizations to use collaborative approach with patientcentered care for youth to overcome these complexities. ${ }^{7}$

Recently, collaboration has been done with Egypt and many national and international organizations as $\mathrm{MOH}$, WHO, Universities, NGOS, and USAIDS through providing information regards viral hepatitis in World Hepatitis Day, campaigns, universities and hotlines. ${ }^{13}$

Consequences of HCV infection include chronic infection with HCV which leads to end-stage liver disease, hepatocellular carcinoma (HCC) and liver-related death. Approximately $60 \%-80 \%$ of the patients develop chronic HCV infection and $10 \%-$ $20 \%$ of those patients develop cirrhosis over next 20-30 years of HCV infection. ${ }^{14}$ Liver transplantation may be needed in case of development of HCC from $\mathrm{HCV} .{ }^{15}$ Mode of transmission of $\mathrm{HCV}$ including use unsterilized needle syringe, needle stick injuries, parental drug use, tattooing and hemodialysis. ${ }^{16}$

Egyptian economy has been affected by chronic HCV infection of citizens, through direct costs due to health care costs and indirect costs due to loss of productivity among chronically $\mathrm{HCV}$ infected patients. ${ }^{17}$ Indirect costs are determined by years of life lost due to disability (YLD) and years of life lost due to premature death (YLL) by using WHO disability templates. ${ }^{8} \quad$ Cumulative disability-adjusted life years (DALYs) is also calculated. Direct healthcare costs were calculated from a nationally representative hospital and a disability adjusted life year (DALY) template was used with monetary value assigned to lost life years. Three scenarios were considered: (i) Historical treatment scenario: 50\% SVR; 65000 treated annually, (ii) Current treatment scenario: 90\% sustained virologic response (SVR); 65000 treated annually, (iii) Increased treatment scenario: 90\% SVR; 325000 treated annually by 2018. Cumulative DALYs (2015-2030) under Scenario 1 were estimated at 7.88 million and cumulative costs estimated at $\$ 89.07$ billion. Annual DALYs increased 16\% during 2015-2030 while annual costs more than doubled. Scenario 2 reduced cumulative DALYs and costs by $7 \%$ and $4 \%$, respectively. Under Scenario 3, total costs declined $73 \%$ to $\$ 1047$ million during 2015-2030. As compared to Scenario 1, cumulative DALYs and costs decreased $37 \%$ and $35 \%$, respectively. ${ }^{17}$

The aim of this study is to assess knowledge of new students attending Cairo University towards mode of transmission, possible complications, prevention and sources of information regards $\mathrm{HCV}$ and identify possible related factors. Awareness campaign was followed after the assessment using variety of health education materials in the form of brochures, video films and short seminars regarding $\mathrm{HCV}$ prevalence in Egypt, mode of transmission, 
Table (1): New Cairo university students' knowledge regarding HCV infection nature and possible complications:

\begin{tabular}{lccccccc}
\multirow{1}{*}{\multicolumn{1}{c}{ Statement }} & \multicolumn{3}{c}{ Yes } & \multicolumn{2}{c}{ No } & \multicolumn{2}{c}{ Don't know } \\
\cline { 2 - 7 } \multicolumn{1}{c}{} & $\mathbf{N}$ & $\boldsymbol{\%}$ & $\mathbf{N}$ & $\boldsymbol{\%}$ & $\mathbf{N}$ & $\boldsymbol{\%}$ \\
\hline HCV patient carry the virus life long & 352 & 21.7 & 964 & 59.4 & 306 & 18.9 \\
HCV virus may lead liver failure & 896 & 55.3 & 251 & 15.5 & 473 & 29.2 \\
HCV patient may appear healthy & 757 & 46.7 & 598 & 36.9 & 267 & 16.5 \\
HCV could lead to cancer liver & 827 & 51.4 & 142 & 8.8 & 640 & 39.8 \\
HCV could lead to liver cirrhosis & 963 & 59.9 & 95 & 5.9 & 551 & 34.2 \\
\hline
\end{tabular}

Table (2): New Cairo university students' knowledge regarding HCV mode of transmission:

\begin{tabular}{|c|c|c|c|c|c|c|}
\hline \multirow[t]{2}{*}{ Statement } & \multicolumn{2}{|c|}{ Yes } & \multicolumn{2}{|c|}{ No } & \multicolumn{2}{|c|}{ Don't know } \\
\hline & $\mathbf{N}$ & $\%$ & $\mathbf{N}$ & $\%$ & $\mathbf{N}$ & $\%$ \\
\hline $\begin{array}{l}\text { HCV can be transmitted through blood } \\
\text { transfusion }\end{array}$ & 1430 & 88.1 & 67 & 4.1 & 127 & 7.8 \\
\hline $\begin{array}{l}\text { HCV can be transmitted through hand } \\
\text { shaking* }\end{array}$ & 173 & 10.8 & 1197 & 74.4 & 239 & 14.9 \\
\hline HCV can be transmitted through kissing* & 309 & 19.1 & 965 & 59.8 & 340 & 21.1 \\
\hline $\begin{array}{l}\text { HCV can be transmitted from mother to } \\
\text { fetus during pregnancy }\end{array}$ & 888 & 55.0 & 215 & 13.3 & 513 & 31.7 \\
\hline HCV can be transmitted through ingestion* & 1064 & 65.9 & 269 & 16.7 & 281 & 17.4 \\
\hline $\begin{array}{l}\text { HCV can be transmitted through infected } \\
\text { sharp objects }\end{array}$ & 1307 & 81.1 & 92 & 5.7 & 212 & 13.2 \\
\hline $\begin{array}{l}\text { HCV can be transmitted through contact of } \\
\text { infected persons in work }\end{array}$ & 352 & 21.9 & 912 & 56.9 & 340 & 21.2 \\
\hline
\end{tabular}

\section{Method}

Study setting, design and sampling: The current study is cross sectional in design conducted at students' hospital affiliated to Cairo University. All freshmen students for the academic year 2016/2017 attending for their comprehensive preacceptance medical examination in Cairo University for the academic year 2016/2017 were targeted. The study was conducted as part of an awareness campaign entitled "Cairo University free from Hepatitis C". The department of Public Health and community medicine was responsible for the awareness campaign to enhance students' knowledge about $\mathrm{HCV}$.

A quota sample of 1649 freshman Cairo University attendees were taken in sequential manner after their approval and subjected to a self-administered questionnaire. The students' age ranged
Data collection tool: Self-administered questionnaire in Arabic was developed and validated by three Public health professors at public health department in Cairo University. It included age, sex of the students, sources of knowledge and $\mathrm{HCV}$ knowledge statements covering $\mathrm{HCV}$ nature, mode of transmission, complications, prevention and treatment. Response to each statement was (true, false or don't know).

A pilot study was conducted on ten students - not included in the analysis - to check understanding and applicability of the questionnaire. The questionnaire was reviewed before and after pilot study. Based on the results, some modifications were made to remove any ambiguity from the questions and make them easier to understand and interpret.

An awareness campaign followed the assessment of knowledge of the students. Variety of health education materials 
Table (3): New Cairo university students' knowledge regarding HCV prevention and treatment:

\begin{tabular}{|c|c|c|c|c|c|c|}
\hline \multirow{2}{*}{ Statement } & \multicolumn{2}{|c|}{ Yes } & \multicolumn{2}{|c|}{ No } & \multicolumn{2}{|c|}{ Don't know } \\
\hline & $\mathbf{N}$ & $\%$ & $\mathbf{N}$ & $\%$ & $\mathbf{N}$ & $\%$ \\
\hline $\begin{array}{l}\text { Infection control measures at dentist } \\
\text { could prevent } \mathrm{HCV} \text { infection }\end{array}$ & $\begin{array}{r}132 \\
2\end{array}$ & 82.0 & 137 & 8.5 & 154 & 9.5 \\
\hline HCV has an available vaccine ${ }^{*}$ & 928 & 57.4 & 230 & 14.2 & 458 & 28.3 \\
\hline Herbs could play a role in $\mathrm{HCV}$ treatment* & 861 & 53.2 & 170 & 10.5 & 588 & 36.3 \\
\hline
\end{tabular}

were used in the form of brochures, video films and short seminars. They were developed by public health department staff members, it was revised and approved by Head of Public Health Department, Cairo University. Health education materials in (Arabic) covered the following items: HCV prevalence in Egypt, mode of transmission, complications, lines of prevention and control of the diseases.

Table (4): Correlation between age of the students and their level of $\mathrm{HCV}$ knowledge:

\begin{tabular}{lcc}
\hline $\begin{array}{c}\text { Knowledge } \\
\text { percent score }\end{array}$ & P value \\
\hline Age & $\mathrm{r}=0.069$ & $0.009^{*}$ \\
\hline${ }^{*}$ p value $<0.05$ & & \\
\hline
\end{tabular}

Data Management and Statistical Analysis: The data was coded, entered and analyzed using the statistical package SPSS version 24. Data was cleaned and double checked. Number and percent were used to summarize qualitative variables. Appropriate summary measures were used to summarize quantitative variables. Independent sample $\mathrm{t}$ test was used to compare between groups. $\mathrm{P}$ value $\leq 0.05$ was considered as statistically significant. A total knowledge score was developed. Each correct answer scored one grade, while no answer or did not know was scored zero. Total score out of 15 was calculated. Then Percent score was calculated for easier interpretation and comparison.

\section{Ethical Considerations:}

All participants were treated according to Helsinki declarations of biomedical ethics; Verbal consents were taken from the participants after explanation of the
Table (5): Total HCV knowledge percent score by different source:

\begin{tabular}{|c|c|c|c|}
\hline \multirow{2}{*}{ Variable } & \multirow{2}{*}{\multicolumn{2}{|c|}{$\begin{array}{c}\begin{array}{c}\text { Knowledge } \\
\text { percent score }\end{array} \\
\text { Mean } \pm \text { SD } \\
\end{array}$}} & \multirow{2}{*}{$\begin{array}{c}\mathbf{P} \\
\text { value }\end{array}$} \\
\hline & & & \\
\hline \multicolumn{4}{|l|}{$\operatorname{Sex}$} \\
\hline Male & 51.2 & \pm 17.2 & 0.929 \\
\hline Female & 51.1 & \pm 17.5 & \\
\hline \multicolumn{4}{|c|}{ Source of HCV literacy } \\
\hline \multicolumn{4}{|l|}{ HCWs } \\
\hline Yes & 50.7 & \pm 18.1 & 0.668 \\
\hline No & 51.1 & \pm 17.4 & \\
\hline \multicolumn{4}{|l|}{ TV \& Radio } \\
\hline Yes & 52.4 & \pm 15.5 & 0.182 \\
\hline No & 50.8 & \pm 17.9 & \\
\hline \multicolumn{4}{|l|}{ Internet } \\
\hline Yes & 52.0 & \pm 16.2 & 0.080 \\
\hline No & 50.5 & \pm 18.3 & \\
\hline
\end{tabular}

aim and impact of the study and ensuring confidentiality of data.

\section{Results}

A total of 1649 freshmen Cairo University students were subjected to selfadministered questionnaires. Their age ranged from 16 to 23 years with mean \pm SD of $18.1 \pm 0.6$ years. Nearly two thirds of them were females $(65.4 \%)$. The main source of HCV literacy was the internet (36\%), followed by health care workers $(23.8 \%)$ and TV and Radio (15.8\%).

Total knowledge percent score ranged from zero to 93.3 with a mean of 51 percent and standard deviation of 17.6 percent. Median total knowledge percent score was 53.3 percent and IQR from 40 to 66.7 percent. Only one fifth of the studied students knew the chronic nature of HCV infection. Nearly half of them (46\%) agreed on the asymptomatic 
presentation of $\mathrm{HCV}$ infection. Nearly half of the studied students correctly identified liver cirrhosis, liver failure and hepatocellular carcinoma as complications of HCV infection (59.9\%, $55.3 \%$ and $51.4 \%$ respectively). (Table 1 ) Regarding mode of transmission of HCV virus, most of the students correctly identified transmission through blood transfusion and infected sharp objects ( $88 \%$ and $81 \%$ respectively). Half of the studied students $(55 \%)$ knew that HCV could be transmitted from mother to fetus during pregnancy. Most of them disagreed on transmission of the virus through hand shaking (74\%) or kissing (60\%). Transmission of HCV through ingestion was a common misconception among two thirds $(66 \%)$ of the studied students. (Table 2)

Small percent $(14 \%)$ of them knew the absence of vaccine against HCV. Nearly half of them $(53 \%)$ agreed wrongly on the role of herbs in HCV treatment. (Table 3) Statistically significant weak positive correlation was found between age of the students and their knowledge score $(\mathrm{r}=$ 0.069, $\mathrm{P}=0.009$ ). (Table 4)

No statistically significant difference was found in total knowledge score regarding gender ( $\mathrm{p}=0.929)$ or by different sources of HCV literacy (table 5).

\section{Discussion}

In the present study, we aimed to evaluate the level of hepatitis $C$ knowledge in fresh Cairo University students. Their knowledge towards HCV was well as regards nature of disease, modes of transmission, consequences on liver and absence of vaccine.

As regards mode of transmission of $\mathrm{HCV}$, infected sharp objects are well known factor in the spread of HCV, most of the students in this study were aware of this mode of transmission $(81.1 \%)$. This was consistent with study ${ }^{18}$ that found most of the students had knowledge on the diseases transmitted by contaminated sharp objects e.g. HBV, HCV and HIV. Also this was in agree with the correct knowledge of $(94.7 \%)$ people at a health awareness session according to Minaam et al. ${ }^{19}$ In the contrary, study ${ }^{20}$ done in Sohag showed that the knowledge of students about hepatitis B and C was inadequate before education and improved after participation in the health educational program. This study was conducted in Sohag university including 130 undergraduate students from four faculties completed pre-post symposium test regarding the mode of transmission of HBV \& HCV. It was found the abysmal score regarding mode of transmission of $\mathrm{HCV}$ was $33.3 \%$ in the pre-test compared to posttest, the percentage is increased to $86 \%$. This may be due to different sample size between our study and this study.

The current study revealed that students received their knowledge from internet, health workers, TV and radio $(36 \%, 23.8 \%$ and $15.8 \%$ respectively). It was inconsistent with Razi et $\mathrm{al}^{21}$ that assess knowledge, attitude and practices of university students, regarding hepatitis B and C. This was multi-centre cross sectional study that conducted from January to June 2008. Their main source of information was television. This difference may be due to difference in study period and sample size.

People with HCV infection are often asymptomatic and may not be aware of being infected though they are capable of infecting others. ${ }^{22}$ In the present study, Nearly half of the students knew that persons infected with hepatitis $\mathrm{C}$ can be asymptomatic and appear healthy .This was consistent with study ${ }^{23}$ done among fourth year medical student in University of Dammam, It was cross-sectional study that conducted using a selfadministered questionnaire for assessment of awareness of hepatitis $\mathrm{C}$ virus (HCV) transmission, screening of the population, symptoms, complications, prevention, and treatment. Most of the student knew that infected persons with HCV may be asymptomatic. The overall awareness on $\mathrm{HCV}$ infection was fair. 
Another so important cause of $\mathrm{HCV}$ transmission is the use of unsterilized dental and surgical instruments. Most of the students in this study know that infection control measures at dentists could prevent $\mathrm{HCV}$ infection. Contrary to that, less than half of the students correctly identified these as risk factors according to Minaam et al. ${ }^{19}$

Majority of students regarded blood transfusion as important source of transmission of infection (88.1\%) in this study. This was contrary to study ${ }^{24}$ that assess awareness of hepatitis B, C among students of non-medical universities in Karachi. Five hundred students from 5 different institutes participated in the survey. Most students did not recognize the possible modes of infection of hepatitis $\mathrm{C}$ that includes blood transfusions (55.2\%) as possible modes of transmission. This different may be due to different sample size and different institutes.

Regarding vaccination, more than half of students in this study incorrectly believed that there is a vaccination available for the prevention of hepatitis $\mathrm{C}$ and the same reported by study. $^{24}$ Most $(51.8 \%)$ incorrectly believed that there is vaccination available for $\mathrm{HCV}$ prevention.

Some misconceptions were observed in the study such as the possibility of $\mathrm{HCV}$ treatment using herbs.

The results of this study showed that there was significant positive correlation between age and knowledge regarding $\mathrm{HCV}$, increasing age was associated with higher score of knowledge. This was consistent with study ${ }^{25}$ that found positive correlation between age and degree of knowledge. This was cross sectional study conducted in five university faculties in Suez Canal University including 698 students that assess their knowledge about $\mathrm{HCV}$ mode of transmission, diagnosis and complications.

\section{Conclusion and} recommendation:
Overall, moderate level of knowledge regarding $\mathrm{HCV}$ was observed among studied Cairo University students. Students have some misconceptions regarding mode of transmission, dealing with the infected persons and treatment of $\mathrm{HCV}$ infection.

The role of health care workers in the dissemination of knowledge $\mathrm{C}$ hepatitis is smaller compared to Internet and Mass Media. It is recommended to empower health care works with appropriate communication and health education skills to improve public awareness regarding $\mathrm{HCV}$. In addition to monitoring relevant information disseminated through Mass Media and internet. (MHealth)

Funding: This work was supported by the Department of Public Health and Community Medicine -Faculty of Medicine Cairo University.

Conflict Of Interest: None declared.

Acknowledgment: We would like to thank Dr Faten Mohamed El Henaway Assistant lecturer of Public health and Community Medicine for her support in finalizing the manuscript. We extend our thanks also to the Public health and Community Medicine Department Faculty of Medicine Cairo University Research Consortium for their support in this work.

\section{References}

1-Marais F,Minkler $M$,Gibson $\mathbf{N}$, Mwau B ,MehtarS,Ogunsola F, et al .Acommunity engaged infection prevention and control approach to Ebola ,Health Promot Int. 2016 Jun;31(2):440-9

\section{2-Castro Sanchez E, Chang PW ,} VilaCandel $\mathbf{R}$, Escabedo AA, HomlesAH.Health literacy and infectious diseases :why does it matter.International Journal of infectious diseases ;2016.43 :103-110. 
3-Shannon $\mathrm{S}$. Working together to understand community health literacy .Cognet Medicine;2017 .4:1364887.

4-D"EathM, BarryMM, Sixsmith J -Rapid evidence review of interventions for improving health literacy. Stockholm .European Centre for Disease Prevention and Control;2012.

5-Coughlin SS . Test, Listen, Cure" (TLC) Hepatitis C Community Awareness Campaign, JMIR Res Protoc;2015 Jan-Mar. 4(1): e13.

6- -Karimi-Sari H, Tajik M, Bayatpoor ME, Alavian SM. Increasing the Awareness of the General Population: An Important Step in Elimination Programs of Viral Hepatitis. Am J Gastroenterol;2017.112(2): 393-5.

7- Dube A , Harris G , Gahagan, J , Doucet S.Bridging the silos in HIV and Hepatitis C prevention: a crossprovincial qualitative study,Int J Public Health; 2017. 62(7): 739-746.

8-World Health Organization.New hepatitis data highlight need for urgent global response. News release.Available

from

http://www.who.int/mediacentre/news/rel eases/2017/global-hepatitis-report/en/

9- Hart -Malloy,R,Carrascal ,A,DiRienzoAG,Flanigan

C, McClamroch K, Smith L, . Estimating HCV prevalence at the State level: A call to increase and strengthen current surveillance systems. Am J Public Health. 2013 August; 103(8): 1402-1405. 10-Blach S, Zeuzem S, MannsM,Altraif I, Duberg AS, $\boldsymbol{A l}$ Ghazzawi I et al . Globalprevalence and genotype distribution of hepatitis $\mathrm{C}$ virus infection in: a modelling study. Lancet Gastroenterol Hepatol;2016 .2(3):16117.

11- El ZanatyF .Egypt Health Issue Survey. Knowledge and prevalence of hepatitis B and C;2015. Ch 3 P 25-49.

12-Tucker JD, Bien CB, Peeling RW.Point-of-care testing for sexually transmitted infections: recent advances and implications for disease control. Curropin Infect;2013.26(1):73-79.

13-MOHP. Plan of action for the prevention, care and treatment of viral hepatitis. Viral hepatitis plan of action overview:Educating providers and communities to reduce transmission of viral hepatitis;(2014-2018). p 50.

14-Westbrook RH and DusheikoG. Natural history of hepatitis C. J Hepatol; 2014. 61(1):S58-S68.

15-SanyalAJ.The Institute of Medicine report on viral hepatitis: a call to action. Hepatology;2010.51(3):727-728.

16-Atlam SA, Elsabgh HM, Shehab NS.Knowledge, attitude and practice of Tanta University Medical Student towardhepatitis B and C. Int J Res Med Sci ;2016. 4 (3):749:756.

17-Estes C, Abdel-Kareem M, AbdelRazek W, Abdel-Sameea E, AbuzeidM,Gomaa A et al .Economic burden of hepatitis $\mathrm{C}$ in Egypt: the future impact of highly effective therapies. Aliment PharmacolTher;2015. 42(6):696-706.

18-Mohamed S A and Wafa A M : The Effects of an Educational Program on Nurses Knowledge and Practice Related to Hepatitis C Virus: A Pre-test and Posttest Quasi-Experimental Design. Australian Journal of Basic and Applied Sciences; 2011. 5(11): 564-570,

19- Minaam A, Muhammad F, Ahmed H, Sajjad R, Lubna S. Frequency and awareness of hepatitis B and C in visitors of hepatitis awareness Mela J Pak Med Assoc; 2010 .60:1069-71

\section{0-Abd El-Nasser G and Abed El baset}

E: Assessment of Students Knowledge and Attitude Toward Hepatitis B and C in Sohag University/Egypt. Journal of nursing sciences; 2013.Vol. 3 No. 1.

\section{1-Razi A,Rahman RU,Naz S, Ghafoor} F and Khan MAU.Knowledge, attitude and practices of university students regarding Hepatitis B and C .Journal of 
agricultural and Biological Science ;2010.Volume.5,NO .4.

22-World Health Organization (WHO)

.Hepatitis C; $2015 . \quad$ Available from: http://www.who.int/mediacentre/fa ctsheets/fs164/en/

23-Almansour AH,Darwish MA,Abdel Wahab MM:Hepatitis $C$ infection awareness among fourth year medical students at university of Dammam.Journal of family and community Medicine ;2017.Vol 24,issue 1: 49-54.

24-_Rafiq A,Fatima S,Masood B,Khan RA,Khan FA,Liaquil A et al. Awareness of hepatitis B and C among students of nonmedical universities in Karachi.Asian Biomedicine; 2015.9:155-159.

25-Elsayed H,Mehanna S, Hassan A, Hassan A,Sheded M,Abdel Fattah $\mathbf{M}$ et al. knowledge,perception and practices of Suez Canal University students regarding Hepatitis $\mathrm{C}$ virus infection risk and means of prevention.Int J Clin MicrobiaL Biochem Technol.2019;2:020-027. 